RESEARCH NOTE

\title{
Phase I and II Open Clinical Trials of a Vaccine Against Leishmania chagasi Infections in Dogs
}

\section{Wilson Mayrink, Odair Genaro/ ${ }^{+}$, João Carlos França Silva, Roberto Teodoro da Costa, Wagner Luis Tafuri*, Vicente Paulo C Peixoto Toledo**, Alexandre Rotondo da Silva***, Alexandre Barbosa Reis***/++, Paul Williams, Carlos Alberto da Costa**}

\footnotetext{
Departamento de Parasitologia *Departamento de Patologia Geral, Instituto de Ciências Biológicas **Departamento de Análises Clínicas e Toxológicas, Faculdade de Farmácia, Universidade Federal de Minas Gerais, Av. Antônio Carlos 6627, Caixa Postal 486, 31270-901 Belo Horizonte, MG, Brasil ***Departamento de Ciências Biológicas,

Universidade Federal de Ouro Preto, Ouro Preto, MG, Brasil
}

Key words: canine visceral leishmaniasis Leishmania chagasi - vaccine - dogs

Visceral leishmaniasis occurs in tropical and subtropical parts of the world and is most commonly found in rural areas. In the Americas, more than $90 \%$ of the cases have been recorded in Brazil. The disease can be controlled by treatment of all human cases, elimination of infected dogs and application of insecticide to the walls of dwellings and peridomestic buildings (PA Magalhães et al. 1980 Rev Inst Med Trop São Paulo 22: 197-202). After applying these measures, constant vigilance must be exercised. Control measures must be applied again as soon as there is evidence of the reactivation of the transmission cycle.

As alternative control measures some authors have emphasized the importance of immunopro-

This work received financial support from Fundação Banco do Brasil, FAPEMIG and BIOBRAS.

${ }^{+}$Corresponding author. Fax: +55-31-441.6909

${ }^{++}$Fellowship of CNPq

Received 26 March 1996

Accepted 16 August 1996 phylaxis for canine visceral leishmaniasis (CVL) (MCA Marzochi et al. 1985 Mem Inst Oswaldo Cruz 80: 349-357, L Monjour et al. 1985 CR Acad Sc Paris 301: 803-806). Observations in Europe, however, have produced contradictory results. The vaccine used by Monjour (loc. cit.) and D Frommel et al. (1988 Infect Immun 56: 843) protected mice against Leishmania mexicana and $L$. major, and was found to stimulate the production of neutralizing antibodies when given to dogs (S Dunan et al. 1989 Parasite Immunol 11:397-402). A similar vaccine incorporating $L$. infantum (semipurified and lyophilized) was used in a pilot study of domestic dogs in an endemic area of CVL (BV Ogunkolade 1988 Vet Parasitol 28: 33-41). Surprisingly, vaccinated dogs were found to be more susceptible to infection than the controls. In Brazil, W Mayrink et al. (1990 Rev Inst Med Trop São Paulo 32: 67-69) found that dogs can be partially protected against cutaneous leishmaniasis by a vaccine prepared from a single stock of $L$. braziliensis.

Presently, this line of study has been developed to explore protection of dogs against infection with L. chagasi. In order to evaluate the safety (phase I) and immunogenicity/efficacy (phase II) of this vaccine against $C V L$, we carried out experiments in dogs with experimental challenge of promastigotes of $L$. chagasi (strain MHOM/BR/ 72/BH46) after immunization.

Thirty one 4 month-old laboratory-reared mongrel dogs of both sexes were immunized against parvovirosis, leptospirosis, distemper, parainfluenza and hepatitis and treated with mebendazol for intestinal helminthic infections.

The Leishmania vaccine was composed of merthyolated sound-disrupted promastigotes of $L$. braziliensis, strain MCAN/BR/72/C348 (Mayrink loc. cit.). The promastigotes were cultured in NNN/ LIT media (EP Camargo 1964 Rev Inst Med Trop São Paulo 6: 43-100). The flagelates were submitted to ultra-sound during $1 \mathrm{~min}$ at 40 watts, in an ice bath. The process was repeated three times, at 1 min intervals. Total nitrogen content was then determined and the extracts were diluted in saline mixed with thimerozal $(1: 10,000)$, adjusting the final concentration to $240 \mu \mathrm{g}$ of total N/ml. Bacillus Calmete Guérin (BCG - Fundação Ataulfo de Paiva, Rio de Janeiro) was added as an adjuvant.

The phase I trial was carried out on 12 nonimmune dogs, and the aim was to evaluate the kinetics of the inflammatory skin reaction to the vaccine and BCG and to determine localized and systemic side effects. Four groups composed of three dogs each were used. In Group I dogs received an injection of vaccine containing $600 \mu \mathrm{g}$ protein mixed with $400 \mu \mathrm{g}$ of BCG. Animals in groups II, 
TABLE

Parasitological and immunological observations on 19 dogs challenged with promastigotes of Leishmania chagasi after immunization with a vaccine against visceral leishmaniasis

\begin{tabular}{|c|c|c|c|c|c|}
\hline Group & Dog & $\begin{array}{c}\text { Parasite } \\
\text { isolation }^{a}\end{array}$ & $\begin{array}{c}\text { Stimulation } \\
\text { index of lymphocyte } \\
\text { proliferation assay } b\end{array}$ & $\begin{array}{c}\text { Reciprocal } \\
\text { of IFAT titres }\end{array}$ & $\begin{array}{r}\text { Conclusion } \\
\text { (infection) }\end{array}$ \\
\hline \multirow{9}{*}{ Vaccinated } & 1 & Negative & 14.3 & Negative & No \\
\hline & 2 & Negative & 13.0 & Negative & No \\
\hline & 3 & Negative & 5.6 & Negative & No \\
\hline & 4 & Negative & 3.3 & Negative & No \\
\hline & 5 & Negative & 5.6 & Negative & No \\
\hline & 6 & Negative & 3.3 & Negative & No \\
\hline & 7 & Negative & 6.6 & Negative & No \\
\hline & 8 & Positive & 1.9 & $1: 160$ & Yes \\
\hline & 9 & Negative & 3.9 & Negative & No \\
\hline \multirow{10}{*}{ Control } & 10 & Negative & 4.7 & Negative & No \\
\hline & 11 & Negative & 1.0 & $1: 360$ & Yes \\
\hline & 12 & Negative & 1.7 & $1: 640$ & Yes \\
\hline & 13 & Negative & 2.1 & $1: 360$ & Yes \\
\hline & 14 & Positive & 2.1 & $1: 1280$ & Yes \\
\hline & 15 & Positive & 1.7 & $1: 160$ & Yes \\
\hline & 16 & Positive & 1.3 & $1: 2560$ & Yes \\
\hline & 17 & Negative & 0.8 & $1: 640$ & Yes \\
\hline & 18 & Positive & 0.7 & $1: 1280$ & Yes \\
\hline & 19 & Positive & 0.8 & $1: 1280$ & Yes \\
\hline
\end{tabular}

$a$ : final results obtained on the day of the animals' necropsies; $b$ : results obtained after the third dose of the vaccine; $c:$ IFAT $=$ immunofluorescent antibody test. 